\title{
Javier Pérez-Embid Wamba, Culto funerario Y Registro neCRológico de la CATEDRAL DE SEVILLA (Siglos XIII-XV). Comité Español de Ciencias Históricas/Dykinson, Madrid, 2015, 427 pÁginas. ISBN: 9788490854082.
}

\author{
María José Lop OTÍN \\ Universidad de Castilla-La Mancha
}

Pocas instituciones civiles o eclesiásticas admiten tantas lecturas como las catedrales. El historiador que se acerca a ellas puede escoger realizar un estudio de corte tradicional que repase su estructura y funcionamiento interno; valorar, y así se ha hecho con profusión, su peso económico y la forma en que explotaban los ricos patrimonios que administraban; conocer, individualizándolos si se puede, a los integrantes de los cabildos y su grado de influencia social y política; e investigar la forma en que estos templos se proyectaban en su entorno inmediato mediante diversas iniciativas culturales, asistenciales y, desde luego, religiosas. Precisamente, una de las más interesantes vías de análisis que admiten las catedrales es la que se centra en la actividad esencial para la que se levantan estas inmensas montañas de piedra: dar culto a Dios y atender los complejos servicios litúrgicos que diariamente se celebran en ellas, tal como recogen al detalle los estatutos capitulares. Entre esos oficios ocupan un lugar destacado los que tienen que ver con la muerte, a la que las catedrales ofrecen tanto un espacio material para el descanso del cuerpo como el consuelo de la oración a través de las numerosas misas y aniversarios que se decían en sus capillas y altares por la salvación de las almas. Esta es justamente la línea de trabajo que nos presenta el libro que aquí se reseña. Su autor, el profesor Javier Pérez-Embid, catedrático de Historia Medieval de la Universidad de Huelva, vuelve casi cuarenta años después a retomar el tema que fue objeto de su memoria de licenciatura en 1977: el estudio de la iglesia catedral de Sevilla en la Baja Edad Media. En las décadas que median entre esas dos publicaciones ha seguido cultivando la historia de la Iglesia en publicaciones sobre la la Orden del Císter o el culto a los santos en las tierras de Castilla y León, sin dejar de profundizar en el conocimiento de la Andalucía medieval. Ahora, a la luz del avance en los estudios sobre catedrales y cabildos hispanos, ha decidido retomar y revisar aquella investigación inicial y dar un paso más. Se sirve para ello del conocido como Libro Blanco de la catedral de Sevilla - en realidad denominado Libro de las dotaçiones de la eglesia de Sevilla-, texto que ya ha sido 
explotado por él y otros historiadores para estudiar el patrimonio capitular y la geografía administrativa de la diócesis, y que ahora se utiliza "en el contexto de la investigación sobre las actitudes ante la muerte y el despliegue de la memoria en las sociedades medievales" (p. 10). El citado Libro -del que no se conserva el original, sino dos copias posteriores, una en pergamino, en el archivo de la catedral hispalense, y otra en papel, en la Real Academia de la Historia- es un compendio de noticias sobre el templo, que arranca con un obituario elaborado en 1411 por el prior, racionero y contador Diego Martínez para regular esa parte del oficio litúrgico; continúa con una compilación de estatutos capitulares, a la que sigue la ordenación del reparto del diezmo; y finaliza con un nuevo necrologio, que incluye las entradas añadidas en los siglos XVI y XVII. Es el primero de esos textos, el obituario de 1411, el protagonista de nuestro libro, protagonismo que se concreta de dos formas: de un lado, porque es la base del estudio que Pérez-Embid realiza sobre el desarrollo del culto funerario de la catedral hispalense; de otro, por la cuidada transcripción y edición que se hace del mismo. Lo cierto es que de las 427 páginas del libro, más de 300 se destinan a este fin.

Al estudio propiamente dicho se dedica el amplio capítulo tercero, "Obituarios y sociedad: la comunidad de los vivos y de los muertos", en el que se repasan los aniversarios, memorias y capellanías dotadas en la catedral de Sevilla desde 1266 hasta comienzos del siglo XVI. Para ese repaso es fundamental la información aportada por tres fuentes: el Curso de los aniversarios y memorias, mandado elaborar por el cabildo en 1366 siguiendo su orden temporal o calendario, el citado Libro de dotaçiones de 1411, que las registra según un criterio espacial, y los añadidos que se hicieron a éste entre 1421 y 1514. En el texto hay constantes referencias al soporte material de este culto funerario, el propio edificio catedralicio, que evoluciona desde el templo mudéjar inicial hasta la nueva fábrica gótica levantada a lo largo del siglo XV. Sus 37 capillas y 7 altares, de cuyas advocaciones se hacen interesantes comentarios, estaban destinados a albergar los enterramientos y servicios fúnebres encargados por reyes, prelados, diversos sectores del clero catedralicio, caballeros pertenecientes a los linajes locales y particulares varios, entre los que están representados muchos oficios artesanales de la ciudad. Esas dotaciones, que conforme avanza el siglo XV superarían los 470 aniversarios y las 770 memorias asentadas en 1366, se apoyaban en los bienes rústicos y urbanos que cada uno de los fundadores legaron en sus testamentos a la catedral con el fin de satisfacer las tarifas establecidas para la celebración de los correspondientes ritos fúnebres. De todo ello se da cuenta a lo largo del estudio, constatándose los abultados ingresos que este culto funerario reportaba a la corporación capitular.

Como ya he dicho este documentado capítulo, al que solo le hubiera faltado un apartado conclusivo que recapitulara el gran caudal de noticias ofrecidas por el autor, se complementa en la parte segunda de la obra con la transcripción del Libro de las dotaçiones de la eglesia de Sevilla, 63 folios de gran interés que se suman a las ediciones ya conocidas procedentes de otras catedrales hispanas, si bien en nuestro país "una buena porción de los documentos necrológicos custodiados en los archivos aún no ha sido publicada" (p. 82). El autor ha incluido además unos útiles índices que van de los habituales ono- 
mástico y topográfico, a otros que recogen los oficios y cargos de los fundadores, los bienes adscritos al culto funerario o la liturgia asociada a esos aniversarios y memorias. Antes de abordar esta parte nuclear del trabajo, el libro arranca con dos capítulos introductorios que repasan la trayectoria de la catedral sevillana desde mediados del siglo XIII al XV y sirven de marco al estudio sobre el obituario. El primero, titulado "La Iglesia de Sevilla, entre su restauración y el fondo de la crisis bajomedieval", refleja el primer siglo y medio de vida de la sede hispalense, apuntando las líneas esenciales del gobierno desarrollado por sus arzobispos, desde Raimundo de Losanna (1259-1286), verdadero impulsor de la cristianización de la ciudad, a Alfonso de Egea (1403-1417), en cuyo pontificado se elabora el Libro de las dotaçiones. El segundo capítulo, "El cabildo catedral ante los tiempos nuevos", es una revisión del artículo que el propio Pérez-Embid publicó en 1977 en la revista Hispania Sacra, que ahora se amplía con nuevas referencias bibliográficas y diferentes planteamientos, aunque sigue apoyándose en la información aportada por la compilación de estatutos bajomedievales incluida en el Libro Blanco catedralicio. De entre sus contenidos interesa especialmente el apartado que analiza la liturgia desarrollada en la catedral durante el periodo bajomedieval, detallando su calendario y tabla de celebraciones, y la variada oferta (rezo de las horas canónicas, celebración de la eucaristía, solemnes recorridos procesionales) que toda catedral proponía con el fin de dar la máxima solemnidad a sus oficios cultuales.

Finalmente, el libro concluye con cuatro apéndices que abundan en la información sobre el culto funerario en la catedral de Sevilla. Los dos primeros completan las noticias del Libro de dotaçiones de 1411, pues ofrecen, no el texto completo, pero sí algunos índices de los dos obituarios que anteceden y preceden a aquél: el mencionado Curso de los aniversarios y memorias que ha la iglesia de Sevilla en 1366 y las dotaciones registradas también en el Libro Blanco comprendidas entre 1520 y 1639. El tercer apéndice transcribe el ceremonial que seguía la catedral en las celebraciones de difuntos y el cuarto la Protestaçion mucho provechosa para el que está enfermo, oración compuesta por San Anselmo de Canterbury a fines del siglo XI, cuya traducción al castellano realizada a mediados del XV debía leerse a los moribundos. A todos ellos se alude en diferentes momentos del trabajo, por lo que son un buen complemento a sus contenidos.

En suma, estamos ante una relevante obra, realizada con rigor y gran aparato crítico, fundamental para descubrir una faceta más de la catedral de Sevilla, así como para lanzar una nueva mirada sobre el siempre inquietante universo de la muerte y la forma en que ésta era asumida, planificada, reglamentada y conmemorada por los vivos. La "invasión" del pavimento de las iglesias por tantos enterramientos y la "inflación" de misas y sufragios que registran los obituarios y libros de aniversarios custodiados en los archivos eclesiásticos merecen toda nuestra atención por dos razones: porque suman contenidos al conocimiento de la complicada liturgia funeraria medieval y porque nos aproximan a la sociedad que la "consume". De ahí que esta obra, como muy bien recoge su capítulo central, sea un estímulo para avanzar en la comprensión de la "comunidad de los vivos y de los muertos" que tenía como referencia a la catedral de Santa María $\mathrm{y}$, por añadidura, de la sociedad sevillana bajomedieval en su conjunto. 
